Discussion Paper No. 698

\title{
THE MEASUREMENT OF SOCIAL WELFARE
}

\author{
Atsushi Tsuneki
}

September 2007

The Institute of Social and Economic Research Osaka University

6-1 Mihogaoka, Ibaraki, Osaka 567-0047, Japan 


\title{
The Measurement of Social Welfare
}

\author{
Atsushi Tsuneki* \\ Institute of Social and Economic Research, Osaka University
}

J EL classification: H20; D61; D63

Keywords: Social Welfare, Deadweight Loss, Measurement, Second Order Approximation

*Corresponding Author. Institute of Social and Economic Research, Osaka University, 6-1, Mihogaoka, I baraki, Osaka, 567-0047 J apan.

Tel.:+81-6-6879-8562; Fax: 81-6-6878-2766;

e-mail: tsuneki@iser.osaka-u.ac.jp 


\begin{abstract}
This paper derives a basic formula for the measure of social welfare, a second order approximation to the difference of the value of the Bergson-Samuelson social welfare function between the socially optimal resource allocation and the one in the present suboptimal economy. We discuss pros and cons of our approach for the measurement of welfare compared with other approaches to applied welfare economics, especially the measurement of deadweight loss.
\end{abstract}




\section{Introduction}

The purpose of this paper is to present our basic formula for the measure of social welfare and discuss its pros and cons compared with other approaches to applied welfare economics. Up to now, approaches for measuring the economic performance of the society chiefly concentrated to the measurement of inefficiency such as deadweight loss. In some circumstances, however, it becomes essential to evaluate the equity aspect of the economic policy at the same time as efficiency. We present a methodology for evaluating the social welfare directly instead of evaluating the efficiency loss to answer the question.

We introduce our model in the next section. In section 3 , our point is elaborated by taking a second order approximation to the linear social welfare function when tax distortions prevail. In section 4, the economic implications of our approach are discussed, especially in comparison with literatures on the measurement of deadweight loss, which include Hotelling (1938), Hicks (1942), Allais (1943, 1977), Boiteux (1951), Debreu (1951, 1954), Harberger (1964), and Diewert $(1981,1984,1985)$. Section 5 briefly concludes.

\section{The Model}

Let us set up the model of our economy. There are $H$ consumers having quasi-concave utility functions $f^{h}\left(x^{h}\right), h=1, \ldots, H$ defined over a translated orthant $Q^{h}$ where $x^{h} \equiv\left(x_{1}^{h}, \ldots, x_{N}^{h}\right)^{T}$ is a consumption vector of goods $1, \ldots, N$ by the $h$-th consumer. The initial endowment vector of the $h$-th consumer is given by $\bar{x}^{h}, h=1, \ldots, H$. There are $K$ firms and firm $k$ produces $y^{k}$ using the production possibilities set $S^{k}, k=1, \ldots, K$, which are subsets of the 
$N$-dimensional nonnegative orthant and satisfies standard regularity properties.

We define the expenditure function: ${ }^{1}$

$$
m^{h}\left(p, u_{h}\right) \equiv \min _{x}{ }\left\{p^{T} x^{h}: f^{h}\left(x^{h}\right) \geq u_{h}\right\}
$$

where $p\rangle\rangle 0_{N}$. See Diewert (1982; 554) for the regularity properties that must be satisfied by the functions $m^{h}$.

The profit function $\pi^{k}, k=1, \ldots, K$ is defined as

$$
\pi^{k}(p) \equiv \max _{x}\left\{p^{T} y: y \in S^{k}\right\}, \quad k=1, \ldots, K .
$$

The regularity properties of the profit function are summarized in Diewert (1982; 580-1).

We assume below that the production possibilities sets $S^{k}, \quad k=1, \ldots, K$ are convex. We also assume for simplicity that markets are compl ete and that the only source of distortions is indirect taxes levied on consumers. Extensions of these assumptions are not difficult. See Diewert (1983, 1986) and Tsuneki (1987, 1995).

Generally, the desirable properties of the ordering of social states are summarized in the Bergson-Samuelsonian social welfare function (BSSWF hereafter). (See Samuelson (1956) for a discussion of the BSSWF and its properties listed below.) We first assume that the underlying social ordering is compatible with the Pareto partial ordering (i.e., if all individual utilities increase,

\footnotetext{
$\left.{ }^{1} x\right\rangle>0_{N}$ means that each element of the vector $x$ is strictly positive, $x \geq 0_{N}$ means that each element of $x$ is nonnegative, and $x>0_{N}$ means $x \geq 0_{N}$ but $x \neq 0_{N}$. A superscript $T$ means transpose.
} 
then so does social welfare) so that the resulting BSSWF becomes Pareto-inclusive. Suppose also that the evaluation of social states is individualistic (or welfarist); i.e., the utility vector $u$ prevailing at the state is the only information used in the evaluation. Also suppose that the evaluation takes the form of a continuous ordering of utility vectors. Then, Debreu's (1959; 56) representation theorem is applied to get the BSSWF, $S(u)$. Pareto-inclusiveness implies that $S$ is monotone increasing in $u$.

We introduce the value of BSSWF at the socially optimal allocation and its value at the present tax-distorted equilibrium. We call the numerical difference of the value of these two resource allocations BSSW measure of welfare. For the numerical evaluation of the difference of the value of BSSWF to be meaningful, we assume below that each individual's utility is measurable on a cardinal scale with a unique zero and that utility functions are identical. Furthermore, we assume that utilities are interpersonally comparable.2

In deriving the formula for BSSW measure, we first characterize the socially optimal resource allocation in the form of mathematical programming as follows:

$$
\begin{aligned}
& \operatorname{Max}_{x^{h}, y^{k}}\left\{S\left(f^{1}\left(x^{1}\right), f^{2}\left(x^{2}\right), \ldots, f^{H}\left(x^{H}\right)\right) \text { s.t. } \quad \sum_{h=1}^{H} x^{h} \leq \sum_{k=1}^{K} y^{k}\right. \\
& \left.+\sum_{h=1}^{H} \bar{x}^{h} ; y^{k} \in S^{k}, \quad k=1, \ldots K\right\} .
\end{aligned}
$$

Hereafter we strengthen the assumption on the utility functions $f^{h}\left(x^{h}\right), h=1, \ldots, H$, so that they are concave following Negishi (1960). Furthermore we assume that $S$ is concave with respect to $u$ by introducing an

\footnotetext{
2 This kind of assumption is not at all exceptional in the study of public economics and practical policy analysis. See Feldstein(1976; 79). For a more detailed discussion for justifying the assumption of identical utility functions among individuals, see also Mirrlees(1982).
} 
explicit value judgment for equity by the social planner.

At this point, we use the concept of the overspending function $B$ which is defined as

$$
B(q, p, u) \equiv \sum_{h=1}^{H} m^{h}\left(q, u_{h}\right)-\sum_{h=1}^{H} q^{T} \bar{x}^{h}-\sum_{k=1}^{K} \pi^{k}(p) .
$$

In Appendix I, $B$ is restated with its economic interpretation and its useful properties are summarized. Using the Uzawa (1958; 34) - Karlin (1959; 201) Saddle-point Theorem using the definition (1), (2) and (A.1), we can rewrite (3) as follows 3 (the calculation is in Appendix II):

$$
\operatorname{Max}_{u} \operatorname{Min} p \geq 0_{N}\{S(u)-B(p, p, u)\} .
$$

We assume that (i) $\left(u^{0}, p^{0}\right)$ solves (4), (ii) the first order conditions for (4) hold with equality so that $\left.p^{0}\right\rangle 0_{N}$, (iii) $B$ is twice continuously differentiable at the optimum, and (iv) $B_{q q}^{0}+B_{p p}^{0}$ is negative definite. From assumptions (i) and (ii), we find the first order conditions for (4) are:

$$
\begin{gathered}
\nabla_{u} S(u)=\nabla_{u} B(p, p, u), \\
-\nabla_{p} B(p, p, u)-\nabla_{q} B(p, p, u)=0,
\end{gathered}
$$

where $\nabla_{u} S(u) \equiv\left[\partial S / \partial u_{1}, \partial S / \partial u_{2}, \ldots, \partial S / \partial u_{H}\right]^{T}$.

Condition (6) is the equality of demand and supply at the optimum while (5) is the rule to equate the marginal social importance of each person to the inverse of his marginal utility of income (see Negishi (1960)). ${ }^{4}$ Note that the solution depends on $\nabla_{u} S(u)$ implies that a distributive value judgment of the social planner is

\footnotetext{
3 We also assume that the Slater constraint qualification condition applies in this economy; i.e., we require that a feasible solution for (3) exists that satisfies the first $N$ inequality constraints strictly.

${ }^{4}$ With appropriate lump-sum transfers across households, the budget constraints of individuals are satisfied and the government budget constraint is implied by them and (6).
} 
explicitly introduced.

In principle, it is possible to compute socially optimal resource allocation and its associated $S\left(u^{0}\right)$ so that we can compute the BSSF measure globally. The numerical general equilibrium approach by Shoven and Whalley (1972, 1973, 1977) which computes equilibria directly corresponding to various tax and expenditure policies should be helpful in this process. However, an obvious drawback of the numerical general equilibrium approach is that we must have information on global functional forms of utility and production functions. Furthermore, in the numerical general equilibrium approach, very restrictive functional forms are adopted to make global computation possible, and these restrictions are easily rejected in econometric tests using more general functional forms (see J orgenson (1984; 140)).

In contrast, local approximation approach we adopt in the sections that follow, only local information of these functions is required, and it does not involve any numerical computations that are more complicated than a single matrix inversion whereas the global computation of the social optimum often causes substantial numerical difficulties. Therefore in this paper, we concentrate on the study of approximate measures of welfare. Specifically, we derive a second order approximation to the BSSW measure.

\section{Second Order Approximation}

To compute the second order approximation to the BSSW measure around the optimal equilibrium, we first construct a $z$-equilibrium:

$$
\nabla_{u} B(p(z)+t z, p(z), u(z))=\nabla_{u} S(u(z))+\lambda z ;
$$




$$
\left.-\nabla_{q} B(p(z)+t z, p(z), u(z))-\nabla_{p} B(p(z))+t z, p(z), u(z)\right)=0 .
$$

When $z=0,(7)$ and (8) coincide with the first order conditions for the maximum of social welfare (5) and (6), if we define $u(0) \equiv u^{0}$ and $p(0) \equiv p^{0}$. When $z=1$, (8) is a set of equations to show the market clearing conditions at the tax-distorted equilibrium, if $u(1) \equiv u^{1}$ and $p(1) \equiv p^{1}$ are the values prevailing at the observed distorted equilibrium. If we assume that the level of lump-sum transfers from the government to consumers is appropriately chosen, there exist budget constraints for consumers compatible with (7) and (8). (8) and these budget constraints imply the budget balance of the government. When $z=1$, (7) quantifies the 'equity' distortions at the observed equilibrium; i.e., $-\lambda_{h}$ shows the difference between the marginal social importance of the $h$-th person and the inverse of his marginal utility of income. It must be noted that both $\nabla_{u} S(u)$ and the marginal utility of income are not invariant to a monotone transformation of $f^{h}\left(x_{h}\right)$. However, they are adjusted proportionally so that (5) is valid. We must also adjust $\lambda_{h}$ proportionally to $h$ 's marginal utility of income and $\nabla_{u} S(u)$ so that (7) is valid.

Now differentiate (7) and (8) with respect to $z$;

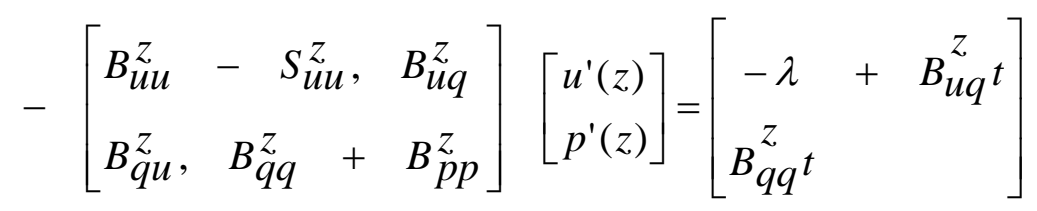

where $B_{i j}^{Z} \equiv \nabla_{i j}^{2} B(p(z)+t z, p(z), u(z)), S_{i j}^{Z} \equiv \nabla_{i j}^{2} S(u(z))$ for $i, j=q, p, u$. Note that $B_{u p}^{Z}={ }_{H \times N}$. Assumptions (iii) and (iv) guarantee, via the Implicit Function Theorem, that once continuously differentiable functions $u(z)$ and $p(z)$ satisfying (9) exist at $z$ close to 0 . Premultiplying $\left[0_{H}^{T}, p(z)^{T}\right]$ to both sides of 
(9) and using property (iii) of the overspending function in Appendix I, we show in Appendix III that

$$
\begin{aligned}
\sum_{h=1}^{H} \nabla_{u} m^{h}(p(z) & \left.+t z, u_{h}(z)\right) u_{h}^{\prime}(z) \\
& =z\left[t^{T} B_{q q}^{Z}\left(p^{\prime}(z)+t\right)+t^{T} B_{q u}^{Z} u^{\prime}(z)\right],
\end{aligned}
$$

is derived. Evaluating (10) at $z=0$, we get

$$
\sum_{h=1}^{H} \nabla_{u} m^{h}\left(p^{0}, u_{h}^{0}\right) u_{h}^{\prime}(0)=0 .
$$

We next differentiate (10) with respect to $z$, and evaluate at $z=0$ to obtain

$$
\begin{aligned}
& u^{\prime}(0)^{T} B_{u u}^{0} u^{\prime}(0)+\sum_{h=1}^{H} \nabla_{u} m^{h}\left(p^{0}, u_{h}^{0}\right) u_{h}^{\prime \prime}(0) \\
& =t^{T} B_{q q}^{0}\left(p^{\prime}(0)+t\right)-p^{\prime}(0)^{T} B_{q u}^{0} u^{\prime}(0) .
\end{aligned}
$$

Premultiplying (9) evaluated at $z=0$ by $\left[0_{H}^{T}, p^{\prime}(0)^{T}\right]$ and adding the resulting identity to (12), we have

$$
\begin{aligned}
& u^{\prime}(0)^{T} B_{u u}^{0} u^{\prime}(0)+\sum_{h=1}^{H} \nabla_{u} m^{h}\left(p^{0}, u_{h}^{0}\right) u_{h}^{\prime \prime}(0) \\
& =p^{\prime}(0)^{T} B_{p p}^{0} p^{\prime}(0)+\left[p^{\prime}(0)+t\right]^{T} B_{q q}^{0}\left[p^{\prime}(0)+t\right] .
\end{aligned}
$$

A second order Taylor approximation to the BSSW measure LBSSW at $z=0$ is as follows:

$$
\begin{aligned}
\mathrm{L}_{\mathrm{BSSW}} \equiv & S(u(0))-S(u(1))=-\left\{\nabla_{u} S\left(u^{0}\right)^{T} u^{\prime}(0)\right. \\
& \left.+1 / 2\left[u^{\prime}(0)^{T} S_{u u}^{0} u^{\prime}(0)+\nabla_{u} S\left(u^{0}\right)^{T} u^{\prime \prime}(0)\right]\right\} .
\end{aligned}
$$

Substituting (5) into (11), we have $\nabla_{u} S\left(u^{0}\right)^{T} u^{\prime}(0)=0$. Substituting it and (5), (13) into (14), we finally have

$$
\begin{aligned}
L_{B S S W} \cong-1 / 2\left\{p^{\prime}(0)^{T} B_{p p}^{0} p^{\prime}(0)+\left[p^{\prime}(0)+t\right]^{T} B_{q q}^{0}\left[p^{\prime}(0)+t\right]\right. \\
\left.+u^{\prime}(0)^{T}\left[S_{u u}^{0}-B_{u u}^{0}\right] u^{\prime}(0)\right\} \geq 0,
\end{aligned}
$$

where the inequality comes from the concavity of $B$ with respect to $p$ and $q$, the positive semidefiniteness of $B_{u u}^{0}$, which is implied by the concavity of the utility functions, the negative semidefiniteness of $S_{u u}^{0}$ implied by the concavity of the 
BSSWF.

\section{Implications}

The remarkable advantage of the approximation approach relative to the numerical general equilibrium approach is that it can be implemented from the derivatives of the overspending function evaluated at the optimum equilibrium, so that we need not know global functional forms for utility and production functions. As an important corollary of this fact, our approximate measure can be derived from any set of flexible functional forms using local information around the equilibrium. However, as long as we must know the derivatives at the optimum as in (15), we must actually know the optimal prices so that we must compute the optimum or we must depend on some 'guessing' process about the values at the optimum. Harberger (1964) suggested replacing these (unobservable) derivatives by those which are evaluated at the observed distorted equilibrium, since they can be calculated using data prevailing at the observed equilibrium.

We now compare the empirical implementability of $L_{B S S W}$ in (15) and (9) and the usual approximate deadweight loss measure represented by Debreu (1954), Harberger (1964) and especially Diewert (1985). Despite their apparent similarities, their meanings are completely different. First, (15) includes a pure equity term $u^{\prime}(0)^{T}\left[S_{u u}^{0}-B_{u u}^{0}\right] u^{\prime}(0)$ which does not exist in the measurement of deadweight loss. Second, $p^{\prime}(0)$ and $u^{\prime}(0)$ calculated from (9) are also affected by the pure equity term $\lambda$.

In (15), we need both the substitution matrices $B_{p p}^{1}, B_{q q}^{1}$ and income effect matrices $B_{q u}^{1}$, tax rates $t$ and the distributional distortion parameters $\lambda$ so that 
the informational requirements are much higher than the usual measurement of deadweight loss. Though it is possible to calculate $B_{p p}^{1}$ and $B_{q q}^{1}$ from local information on ordinary demand curves and supply curves at the distorted equilibrium, we have to know the marginal utility of income $\nabla_{u} B\left(p^{1}+t, p^{1}, u^{1}\right)$ to compute $\lambda$ from (7) or $B_{q u}^{1}$ from ordinary demand curves. As the marginal utility of income is not an operational concept without knowing its original utility function, in light of these observations, we must conclude that the approximate BSSW measure lacks empirical operationality without a knowledge of the original utility functions whereas the measurement of deadweight loss is free from this problem.

It is chiefly for this reason that standard literature has concentrated to the computation of deadweight loss instead of BSSWF. Needless to say, however, the informational advantage of using the deadweight does not mean that it is a superior measure to the BSSW measure of welfare. As long as we can measure the difference between the first order weight of a BSSWF and the inverse of the marginal utility of income, the same type of analysis in the measurement of deadweight loss can be carried out using a BSSWF. As we have stressed thus far, adopting a BSSWF is superior to measuring deadweight loss for the evaluation based on the BSSWF can capture both efficiency of equity aspect of the economy.

The only equity-concerned welfare measure we know is the one originated by Boiteux (1951), which was taken up again recently by Diewert (1981, 1984, 1985). Boiteux'x measure takes the sum of Hicksian (1942; 128) equivalent variations where its reference prices vector is chosen from the viewpoint of normative equity. Unfortunately, this reference prices vector is difficult to compute. In addition, 
the second order approximation of the Boiteux measure requires the information on the hypothetical income vector at the optimum which is difficult to obtain (see Diewert (1984; 36)). In contrast, we can avoid this problem by explicitly assuming the form of utility functions and the comparability of utilities across individuals as value judgment of the social planner. In this sense, our approach to measure the value of BSSWF directly seems much more natural way to evaluate the performance of the economy including both equity and efficiency.

\section{Conclusion}

Present analysis has derived our basic formula for the measure of social welfare. Although it demands more information for its measurement than usual analysis of the deadweight loss, it has an important significance because it can evaluate both efficiency and equity aspect of the economy. We hope that our study serves for the future policy analysis. 


\section{Appendices}

Appendix 1: The Properties of the Overspending Function.

An overspending function, introduced into economics by Bhagwati, Brecher and Hatta (1983; 608) summarizes the general equilibrium relations of an economy within one equation. It may be interpreted as the aggregate net expenditure of consumers facing prices $q$ minus the aggregate profits of firms facing prices $p$. It inherits many useful properties of expenditure functions and profit functions which are exhibited in Diewert (1982). We collect several important properties for later use.

An overspending function is defined by

$$
B(q, p, u) \equiv \sum_{h=1}^{H} m^{h}\left(q, u_{h}\right)-\sum_{h=1}^{H} q^{T} \bar{x}^{h}-\sum_{k=1}^{K} \pi^{k}(p) .
$$

It has the following properties.

(i) $B$ is concave with respect to $p$ and $q$.

(ii) If $B(q, p, u)$ is once continuously differentiable with respect to $q$ and $p$ at $(q, p, u)$, then $\nabla_{q} B(q, p, u)$ is the aggregate net consumption vector and $-\nabla_{p} B(q, p, u)$ is the aggregate net production vector.

(iii) The following identities are valid for any $(q, p, u)$ if $B$ is twice continuously differentiable at $(q, p, u)$ :

$$
q^{T} B_{q q}=0_{N}^{T}
$$

$$
\begin{gathered}
q^{T} B_{q u}=\left(\nabla_{u} B\right)^{T}=\left(\partial m^{1}\left(q, u_{1}\right) / \partial u_{1}, \ldots, \partial m^{H}\left(q, u_{H}\right) / \partial u_{H}\right), \\
p^{T} B_{p p}=0_{N}^{T},
\end{gathered}
$$

where $B_{i j} \equiv \nabla_{i j}^{2} B(q, p, u)$ for $i, j=q, p, u$.

Property (i) follows from the fact that an expenditure function is concave with respect to prices and a profit function is convex with respect to prices. Property 
(ii) is a straightforward consequence of Hotelling's (1932; 594) lemma and the Hicks (1946; 331)-Shephard (1953; 11) lemma. Property (iii) is a consequence of the linear homogeneity of an expenditure function and a profit function with respect to prices.

\section{Appendix II}

In this Appendix, we show that (3) and (4) are equivalent given concave utility functions and convex production sets, provided the Slater constraint qualification holds. In (3), $S(u)$ is assumed to be concave, the set $\left\{x^{h}: f^{h}\left(x^{h}\right) \geq u_{h}\right\}$ is convex from the concavity of $f^{h}\left(x^{h}\right), S^{k}$ is also assumed to be convex and the inequalities are linear. Therefore, (3) is a concave programming problem and the Uzawa-Karlin Saddle Point Theorem is applicable. Rewrite (3) as :

$$
\max _{u, x^{h}, y^{k}} \min _{p \geq 0_{N}}\left\{S(u)+p^{T}\left[\sum_{k=1}^{K} y^{k}+\sum_{h=1}^{H} \bar{x}^{h}-\sum_{h=1}^{H} x^{h}\right]:\right.
$$

$$
\begin{aligned}
& \left.\mathrm{f}^{\mathrm{h}}\left(x^{h}\right) \geq u_{h}, h=1, \ldots, H ; y^{k} \in S^{k}, k=1, \ldots, K\right\}, \\
& \equiv \max _{u} \min _{p \geq 0_{N}}\left\{S(u)+\sum_{h=1}^{H} p^{T} \bar{x}^{h}+\sum_{h=1}^{H}\left[\max -p^{T} x^{h}: \mathrm{f}^{\mathrm{h}}\left(x^{h}\right) \geq u_{h}\right]\right. \\
& \left.\left.+\sum_{k=1}^{K} \max p^{T} y^{k}: y^{k} \in S^{k}\right]\right\} \\
& \equiv \max _{u} \min _{p \geq 0_{N}}\left\{S(u)+\sum_{h=1}^{H} p^{T} \bar{x}^{h}+\sum_{k=1}^{K} \pi^{k}(p)-\sum_{h=1}^{H} m^{h}\left(p, u_{h}\right)\right\}
\end{aligned}
$$

using the definitions (1) and (2). From the definition (A.1), we have (4).

\section{Appendix III}


In this Appendix, we derive (10). Premultiplying both sides of (9) by $\left[0_{H}^{T}, p(z)^{T}\right]$, we have:
(A.7)
$-p(z)^{T} B_{q u}^{Z} u^{\prime}(z)-p(z)^{T}\left[B_{q q}^{Z}+B_{p p}^{Z}\right] p^{\prime}(z)=p(z)^{T} B_{q q}^{Z} t$.

From (A.2), (A.3) and (A.4) evaluated at $(p, q, u)=(p(z)+t z, p(z), u(z))$, we have $p(z)^{T} B_{q q}^{Z}=-z t^{T} B_{q q}^{Z}, p(z)^{T} B_{q u}^{Z}=\left(\nabla_{u} B\right)^{T}-z t^{T} B_{q u}^{Z}$ and $p(z)^{T} B_{p p}^{Z}=0_{N}^{T}$.

Substituting these equations into (A.7), we have (10). 
Acknowledgement: The author thanks Professors W. Erwin Diewert and J ohn

Weymark for their valuable suggestions and support in writing the article. Discussion with Hideki Konishi and the suggestions by Hiroshi Yoshikawa were also very hel pful. The remaining errors are strictly my own responsibility.

\section{References}

Allais, M. (1943). A la Recherche d'une Discipline Economique, Tom I, Paris: Imprimerie Nationale.

Allais, M. (1977). “Theories of General Economic Equilibrium and Maximum Efficiency," pp.129-201 in Equilibrium and Disequilibrium in Economic Theory, E. Schwodiauer, ed., Dordrecht: D. Reidel.

Arrow, K. J . (1951). "An Extension of the Basic Theorems of Classical Welfare Economics," pp.507-532 in Proceedings of the Second Berkeley Symposium on Mathematical Statistics and Probability, J . Neyman, ed., Berkeley: University of California Press.

Bhagwati, J .N., R.A. Brecher and T. Hatta. (1983). "The Generalized Theroy of Transfer and Welfare: Bilateral Transfers in a Multilateral World," American Economic Review 73, pp.606-618.

Boiteux, M. (1951). "Le 'Revenue Distruable' et les Pertes Economiques," Econometrica 19, pp.112-133.

Debreu, G. (1951). "The Coefficient of Resource Utilization,” Econometrica 19, pp.273-291.

Debreu, G. (1954). “A Classical Tax-Subsidy Problem," Econometrica 22, pp.14-22. 
Debreu, G. (1959). Theory of Value, New York: J ohn Wiley.

Diewert, W.E. (1981). "The Measurement of Deadweight Loss Revisited," Econometrica 49, pp.1225-1244.

Diewert, W.E. (1982). "Duality Approaches to Microeconomic Theory," pp.535-599 in Handbook of Mathematical Economics Vol.2, K.J . Arrow and M.D. Intriligator, eds. Amsterdam: North Holland.

Diewert, W.E. (1983). “The Measurement of Waste within the Production Sector of an Open Economy," Scandinavian J ournal of Economics 85, pp.159-179.

Diewert, W.E. (1984). “The Measurement of Deadweight Loss in an Open Economy," Economica 51, pp.23-42.

Diewert, W.E. (1985). “The Measurement of Waste and Welfare in Applied General Equilibrium Models," pp.42-103 in New Developments in Applied General Equilibrium Analysis, J. Pigott and J . Whalley eds. Cambridge: Cambridge University Press.

Diewert, W.E. (1986). The Measurement of Economic Benefits of Infrastructure Services, Lecture Notes in Economics and Mathematical Systems 278. Berlin: Springer Verlag.

Feldstein, M.S. (1976). "On the Theory of Tax Reform," J ournal of Public Economics 6, pp.77-104.

Harberger, A.C. (1964). "The Measurement of Waste," American Economic Review 54, pp.58-76.

Hicks, J .R. (1942). "Consumer's Surplus and Index Numbers," The Review of Economic Studies 9, pp.126-137.

Hicks, J . R. (1946). Value and Capital, 2nd ed. Oxford: Clarendon Press. 
Hotelling, H. (1932). "Edgeworth's Taxation Paradox and the Nature of Demand and Supply Functions," J ournal of Political Economy 40, pp.577-616.

Hotelling, H. (1938). “The General Welfare in Relation to Problems of Taxation and of Railway and Utility Rates," Econometrica 6, pp.242-269.

J orgenson, D.W. (1984). "Econometric M ethods for Applied General Equilibrium Analysis," pp.139-203 in Applied General Equilibrium Analysis, H.E. Scarf and J .B. Shoven eds. Cambridge: Cambridge University Press.

Karlin, S. (1959). Mathematical Methods and Theory in Games, Programming and Economics. Reading, Mass: Addison-Wesley.

Mirrlees, J.A. (1982). “The Economic Uses of Utilitarianism," pp. 63-84 in Utilitarianism and Beyond, A.K. Sen and B. Williams eds. Cambridge: Cambridge University Press

Negishi, T. (1960). "Welfare Economics and Existence of an Equilibrium for a Competitive Economy," Metroeconomica 12, pp.92-97.

Samuelson, P.A. (1947). Foundations of Economic Analysis. Cambridge, Mass: Harvard University Press.

Samuelson, P.A. (1956). "Social Indifference Curves," Quarterly J ournal of Economics 70, pp.1-12.

Shephard, R.W. (1953). Cost and Production Functions. Princeton: Princeton University Press.

Shoven, J .B. and J . Whalley. (1972). "A General Equilibrium Calculation of the Effects of Differential Taxation of Income from Capital in the U.S.," J ournal of Public Economics 1, pp.281-321.

Shoven, J.B. and J. Whalley. (1973). "General Equilibrium with Taxes: A 
Computational Procedure and an Existence Proof," The Review of Economic Studies 40, pp.475-489.

Shoven, J .B. and J . Whalley. (1977). "Equal Yield Tax Alternatives - General Equilibrium Computational Techniques," J ournal of Public Economics 8, pp.211-224.

Tsuneki, A. (1987). "The Measurement of Waste in a Public Goods Economy," J ournal of Public Economics 33, pp.73-94.

Tsuneki, A. (1995). "The Measurement of Waste with Nonconvex Technology," J ournal of Economics 61, pp.83-88.

Uzawa, H. (1958). “The Kuhn-Tucker Theorem in Concave Programming," pp.32 -37 in Studies in Linear and Nonlinear Programming. K.J. Arrow, L.H. Hurwicz and H. Uzawa, eds. Stanford, CA: Stanford University Press.

Varian, H.R. (1974). "Equity, E nvy and Efficiency," J ournal of Economic Theory9, pp.63-91.

Varian, H.R. (1976). "Two Problems in the Theory of Fairness," J ournal of Public Economics 5, pp.249-260. 